\title{
Accounting
}

\section{The role of artificial intelligence on limiting Jordanian commercial banks cybercrimes}

\author{
Rafat Salameh Salameh ${ }^{a^{*}}$ and Khalid Munther Lutfi ${ }^{\mathrm{b}}$
}

aAssociate Professor, Department of Accounting/Faculty of Business/ Al-Balqa Applied University, Al Salt, Jordan ${ }^{b}$ Cost Controller, Master of Business Administration, Al-Balqa Applied University, Al Salt, Jordan

\begin{tabular}{l}
\hline C H R O N I C L E \\
\hline Article history: \\
Received: January 1, 2021 \\
Received in revised format: \\
January 232021 \\
Accepted: February 17, 2021 \\
Available online: \\
February 17, 2021 \\
\hline Keywords: \\
Artificial intelligence Jordanian \\
commercial banks \\
Cybercrime \\
IT Department \\
Internal Auditors
\end{tabular}

\section{A B S T R A C T}

This study aims to investigate the role of applying artificial intelligence in limiting cybercrime in the 13 Jordanian commercial banks listed in the Amman Financial Market, from the point of view of internal auditors and IT. For this purpose, a questionnaire was designed and distributed to the study sample of (849). The number of respondents to the questionnaire reached (230). The data of the questionnaire were analyzed, and their hypotheses were tested using the statistical program (SPSS) through tests of the arithmetic mean, standard deviation, linear, multiple regression, and the T-test for two independent samples. The study found a statistically significant effect for artificial intelligence with its dimensions (Expert Systems, Artificial Neural Network, Genetic Algorithm, Fuzzy logic) in limiting cybercrime in Jordanian commercial banks. It was also found that there were statistically significant differences in both genetic algorithm and cybercrime attributable to the job variable in favor of IT department employees.

\section{Introduction}

Nowadays the rapid spread of technology use has strongly reshaped the world due to the rapid technological progress using a set of advanced modern digital programs and technologies like the internet, artificial intelligence, and blockchain. The digital industrial revolution is expected to rebuild the infrastructure of economic sectors of all kinds to become more sophisticated than it was in the past. It leads to Limiting costs, increasing national income, and improving the level of competitiveness at the global level. The world today is witnessing the information age and the shift to the application of artificial intelligence programs and tools like Expert Systems, Genetic Algorithms, Artificial Neural Networks, and Fuzzy Logic, etc. as they simulate knowledge and skills and can understand human behavior. They are meant to reach information solutions to accounting problems and identify deviations and rationalization of decisions accurately and quickly, especially in the banking sector. The latter has become dependent on providing most of its banking services on artificial intelligence applications due to the accuracy and speed this achieves and the reduction of internal and external fraudulent operations. As the spending on artificial intelligence in the banking sector reached 50.1 billion dollars in 2020 and expected to reach 110billion dollars by 2024 (IDC, 2020 ).

\subsection{Study Problem}

The constant increase in fraudulent operations and electronic crimes such as account seizures, embezzlement from them, alteration of customer data, etc., led to financial losses estimated at about 4 billion dollars annually, 40 percent of which are

* Corresponding author

E-mail address: dr_rafats@bau.edu.jo (R. S. Salameh) 
attributed to electronic commerce fraud or the theft of ATM cards (Varmedja et al., 2019). This has prompted banks and electronic payment service providers to use advanced protection technologies and programs such as Eric's crime-fighting system.

Hence the study problem is explained through the following main question:

Is there a role for artificial intelligence applications represented in (expert systems, neural networks, genetic algorithms, and fuzzy logic) in Limiting cybercrime in Jordanian commercial banks from the point of view of internal auditors and IT department employees? This main question is divided into the following:

1- Do artificial intelligence applications represented in expert systems play a role in Limiting cybercrime in Jordanian commercial banks from the point of view of internal auditors and IT department employees?

2- Do artificial intelligence applications represented in neural networks play a role in Limiting cybercrime in Jordanian commercial banks from the viewpoint of the internal auditors and IT department employees?

3- Do artificial intelligence applications represented in genetic algorithms play a role in Limiting cybercrime in Jordanian commercial banks from the point of view of internal auditors and IT department employees?

4- Is there a role for artificial intelligence applications represented in ambiguous logic in Limiting cybercrime in Jordanian commercial banks from the point of view of the internal auditors and computer department employees?

5- Are there differences between the conclusions of the two categories of internal auditors and IT department employees? Auditors.

\subsection{Hypotheses of the Study}

The study hypotheses are represented by the following main null hypothesis:

$\mathrm{H}_{0}$ : There is no statistically significant role at $\alpha \leq 0.5$ for the applications of artificial intelligence represented in (expert systems, neural networks, genetic algorithms, and fuzzy logic) in Limiting cybercrime in Jordanian commercial banks from the viewpoint of internal auditors and IT department employees.

The nihilistic sub-hypotheses are presented as follows:

$\mathrm{H}_{01}$ : There is no statistically significant role at $\alpha \leq 0.5$ for artificial intelligence applications represented by expert systems in limiting cybercrime in Jordanian commercial banks from the point of view of internal auditors and IT department employees. $\mathrm{H}_{02}$ : There is no statistically significant role at $\alpha \leq 0.5$ for artificial intelligence applications represented in neural networks in Limiting cybercrime in Jordanian commercial banks from the viewpoint of internal auditors and IT department employees.

$\mathrm{H}_{02}$ : There is no statistically significant role at $\alpha \leq 0.5$ for the applications of artificial intelligence represented in genetic algorithms in Limiting cybercrime in Jordanian commercial banks from the viewpoint of internal auditors and IT department employees.

$\mathrm{H}_{03}$ : There is no statistically significant role at $\alpha \leq 0.5$ for the applications of artificial intelligence represented in the vague logic of limiting cybercrime in Jordanian commercial banks from the point of view of internal auditors and IT department employees. $\mathrm{H}_{04}$ : There are no statistically significant differences at the significance level of $\alpha \leq 0.5$ between the internal auditors and IT department employees in commercial banks towards the assumptions of the previous study.

\subsection{The significance and Importance of the study}

It is certain that banks are now more interested in adopting artificial intelligence techniques with unlimited advanced technology which led the sector to face great challenges related to bank safety and durability, customer protection, and information security. The banking sector is often exposed to threats related to cybercrime, fraud and piracy. From this standpoint, this study came to aim at demonstrating the effect of applying artificial intelligence in Limiting fraud in Jordanian commercial banks from the point of view of internal auditors and IT employees.

\section{Theoretical Framework}

\subsection{The concept of artificial intelligence}

Artificial intelligence first appeared in 1956. The American Association for Artificial Intelligence passed the name "Artificial Intelligence Winter" in 1984 to describe a period of time that was characterized by two phases that began with disappointment in society as a result of a sharp decline in funding that led to a serious end to any research in this field (Crevier, 19930).

In the early eighties, artificial intelligence appeared clearly after the success of "expert systems". Its profits were estimated at more than one billion dollars, which encouraged countries to sponsor this research for a period that extended to 1987 . However, 
this did not last for long to relapse again and return again in the nineties with greater success in the fields of logistics and the medical field. This outstanding flourishing period concluded with the first victory of the machine over humans in a game of chess in 10997 (Joyce \& Laurie, 2018, Deesing, 2019). Russell and Norvig (2016) define artificial intelligence as a technology that can be compared with human wisdom and thinking. Kaplan \& Haenlein (2019) defined it as learning systems from data after interpreting them to be used flexibly to reach specified goals. Likewise, Sayamtini (2019) defined it as computer science concerned with simulating the human mind, aiming to deal with linking information from the surrounding environment through various computerized devices and machines. All in all, artificial intelligence is both science and art as it deals and responds to complex problems in all scientific fields, and designs and employs software technologies via computer systems. According to Shnawa and AlBakri (2018), it is an algorithmic way of thinking that makes computers able to solve problems through simple and easy programming languages to describe objects and events (Osman \& Jamil, 2012).

\subsubsection{Types of Artificial Intelligence}

Artificial intelligence projects are classified according to their abilities into three types (Madkour, 2020).

1. Weak AI which is based on simple computer algorithms programmed by humans, but this does not make computers smart despite their smart behavior.

2. Strong AI which demonstrates that a computer's intelligence level meets human intelligence as it is able to deal with any difficulties as efficiently as humans can. It is mentioned that this level has not been reached yet, because it is almost impossible to speculate on the foggy nature of the human mind.

3. Super AI The ambition of artificial intelligence remained focused on reaching the level of human intelligence until big data appeared (Gamoura et al., 2018). Artificial intelligence is still under study as it seeks to outperform human intelligence and find unfamiliar solutions to problems that the human mind cannot. Research is currently tending to produce electronic minds that compete with the human mind and overcome it in all fields, such as wisdom, skills, scientific creativity, and self-learning, and it is also expected that it conducts dialogue naturally and automatically.

\subsubsection{Objectives of Artificial Intelligence}

Artificial intelligence aims to simulate intelligent human behavior through the ability to think and make decisions. (Al-Yajzi, 2019) The British Arab Academy has summarized the goal of artificial intelligence in the ability to make machines capable of processing big data in parallel. Buzerb and Sahnon (2019) explained that artificial intelligence is the ability to diagnose and solve problems related to design and planning. Cazenave (2011) said that artificial intelligence is about creating and introducing new knowledge and practices for decision-making.

\subsubsection{Artificial Intelligence Applications}

The main applications of artificial intelligence are of three types: applications in cognitive science, applications in robotics, and applications in the natural interface as shown below:

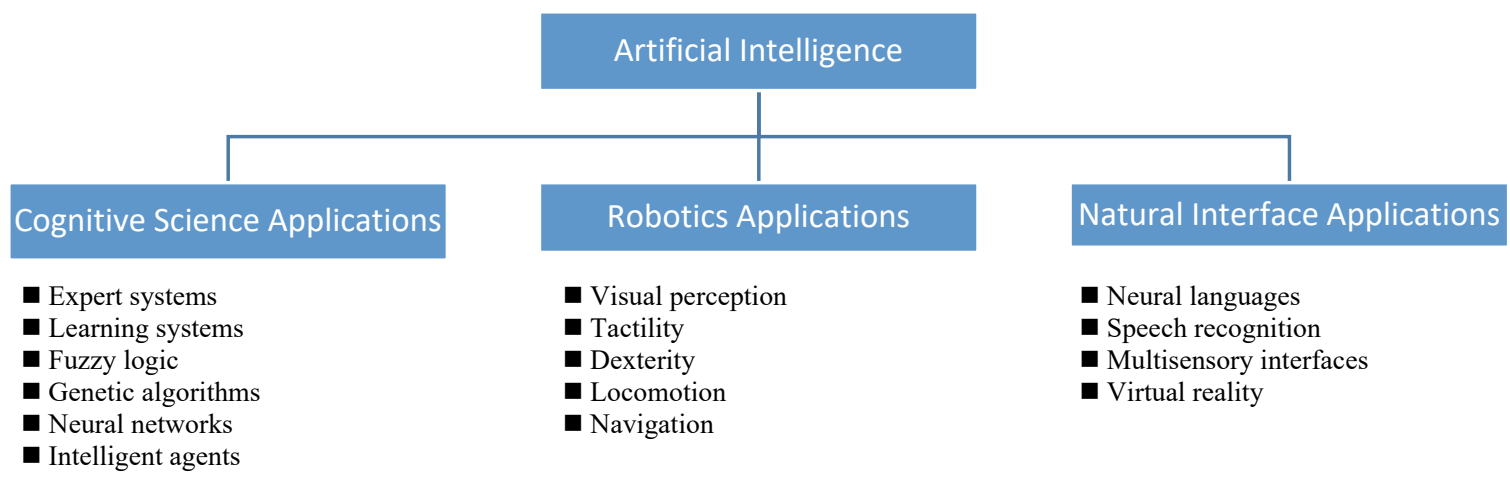

Fig. 1. The main applications of artificial intelligence (O'brien \& Marakas, 2005, 2006)

\section{Expert Systems}

Expert systems provide great facilities in storing and retrieving knowledge in order to provide support to decision-makers, as well as providing information, knowledge and experiences in a fast and timely manner to ensure rationality and rationality to choose the most appropriate among the alternatives (Osman \& Jamil, 2012). Expert systems are divided into systems that work 
as an assistant and they are the least experienced systems that work as a colleague, so they are able to debate and dialogue with the user in order to reach the optimal solution. The true expert systems are those systems that give final solutions without reference to the user and accept their results without argument (Belabed \& Shawi, 2019).

\section{Artificial Neural Networks (ANN)}

It is a paradigm shift that makes machines able to receive audio and visual signals like humans, through a network of multiple nerve layers and through nerve nodes called (nodes), with the aim of reaching deep learning in three strategies:

A- (Supervised learning): It is also the training phase, and in order to obtain optimal results, errors that appear are corrected by comparing audio, visual and textual data with the best results obtained through a process called (Backpropagation), which is a process in which data is tracked backward from the output the desired data entered.

B- (Unsupervised learning): used to process data that is dealt with for the first time, as the network builds a function whose goal is to reduce the error rate as much as possible and reach optimum accuracy.

C- (Reinforcement Learning): Observation is the most important element in this learning style. If the results of data processing are positive, the same mechanism is adopted every time, but if it is found to be negative, the network modifies the processing mechanism in the following times until it reaches the optimal result (Ramya \& Umarani, 2017).

\section{Genetic algorithm}

The word (Genetic) refers to the behavior of algorithms that are close to human behavior. They find solutions based on the way humans solve problems. (O'brien \& Marakas, 2005, 2006) It is also called genetic algorithm, and it is a method created by John Holland in 1975 that artificial intelligence uses to solve problems to find the best solutions (Ismail \& Ghanawi, 2019).

\section{Fuzzy logic}

is a method developed by the scientist Lotfi Zadeh in 1965 to describe the sums with multiple values that lie between zero and the whole digit 1. Before this, classical logic was represented by the error and rightness with zero and whole digit 1 without addressing what is between them. Fuzzy logic is able to deduce and analyze through linguistic or fuzzy variables, and it is very similar to the human method of dealing with imperfect and unclear data problems (Passino \& Reinfrank, 1998).

\subsection{Cybercrime Concept}

American of certified fraud examiners - ACFE has defined fraud as misleading in order to obtain benefits and advantages. This fraud may be represented by the job failure of individuals within the organization in their work through the waste of resources of all kinds, or material embezzle (Abderrahmane, 2017). One of the most common and threatening types of fraud at the global level is Cyber fraud. Also known cybercrime which is committed by using computer systems to penetrate personal information of individuals and companies and using them for personal financial benefit or for other benefiting parties (Morgan, 2018). Cyber fraud has also been defined as using the Internet for the purposes of identity theft or credit cards to obtain money or data without any right (Lee et al., 2018).

\section{Theoretical Framework of Fraud}

1. The Fraud Triangle Theory (FTT) is a theory created by Donald Cressey, a criminologist, in 1953, which states that there must be three elements (pressure, opportunity, and rationalization) in order for the embezzlement to occur.

2. The Fraud Diamond Theory introduced by Wolfe and Hermanson in 2004 as an extended form of the FTT model where capability was added as a new component (Balayan, 2020).

\section{Types of Cybercrime}

Cybercrime can be classified into five types as follows:

(1) Input fraud which occurs in payments and receipts, and it is the easiest and most common.

(2) Processor Fraud, which is about the exploitation of the organization's system for personal purposes by the employees.

(3) Computer Instructions Fraud, which includes stealing software and using it for illegal purposes.

(4) Data Fraud, which is the theft, penetration, or destruction of the personal data of the company or clients, or both, because of the negligence of the employee. 
(5) Output Fraud, which is the manipulation of system outputs, such as changing the name of the payee on checks or amending the amount of money mentioned (Romney et al., 2013).

\subsection{Literature Review}

Ozturk and Usul's (2020) study entitled 'Detection of Accounting Frauds Using the Rule-Based Expert Systems within the Scope of Forensic Accounting' aimed to demonstrate the impact of expert systems in detecting accounting fraud in Turkish companies and its impact on criminal accounting. The researchers used the Benford Law, risk levels and various other criteria in establishing expert systems. The study concluded that the use of expert rules-based systems in the forensic accounting system enabled companies to better discover fraud operations and prevent them from occurring in the future. The study recommended the necessity of applying expert rules-based systems and using them in the field of accounting, auditing and criminal matters. Abhishek's (2019) study was under the title 'Application of Robotics in Accounting and Auditing of Business and Financial Information.' Its objective was to know the benefits of applying robots in accounting and auditing accounts and financial operations in Indian companies. It also had to demonstrate the effect of robots in protection and safety of accounting, financial operations and fairness of financial statements. The study concluded that traditional accounting and auditing methods suffer from several problems such as effort, time, and the difficulty of keeping accounting records for long periods of time. The researcher recommended the necessity of using robots in accounting, financial and auditing operations because of their benefits in saving time, effort and data accuracy in Indian companies. Ebrahiem's Study (2018) under the title 'The Role of Using the Expert Systems in Improving the Quality of the Managerial Decision: A Field Study on The Banks Operating in The Syrian Coast' attempted to demonstrate the use of expert systems with all its dimensions (physical, human, programmatic, and organizational) in improving the quality of administrative decisions in Syrian banks. The study reached the fact that the expert systems had a moral effect on the quality of administrative decisions in Syrian banks.

Jabouri and Salman study (2017) entitled 'Expert systems and their impact on accounting information systems' demonstrate the impact of expert systems on accounting information systems in general and the cost accounting system in particular. The study relied on the questionnaire to collect information distributed to the Iraqi banking sector. The study concluded that there is a significant relationship between the use of expert systems and the development of accounting information systems and called for commercial banks in Iraq to use expert systems because of their positive impact in improving the quality of financial outputs. The study of Al-Beshtawi and AL-Baqmi (2015) was meant to demonstrate the effect of applying expert systems on electronic auditing procedures in Jordanian and Saudi commercial banks from the point of view of external auditors. The study relied on developing a questionnaire that was distributed to the study sample. It figured out that it is important to apply and use expert systems in Jordanian and Saudi commercial banks to facilitate the procedures and effectiveness of auditing. The study recommended the necessity of preserving the assets and files that contain banking business and Limiting the human and material risks associated with using electronic auditing. Omoteso's (2012) research 'The application of artificial intelligence in auditing: Looking back to the future. Expert Systems with Applications' investigated the impact of auditors' use of artificial intelligence systems in order to predict future trends for further research and program development. The paper closed with urging the need to develop artificial intelligence used in auditing, which is reflected in increasing the auditor's efficiency and Limiting the defects that may face the auditor during the audit process. The study focused on the importance of adopting the use of artificial intelligence in the auditing process and assessing the impact of artificial intelligence on the design and monitoring of the internal control system.

\section{Methodology}

To achieve the objectives of the study, the descriptive and analytical approach was used to describe the issue, analyze the data and investigate the relationship between its components and the opinions raised about it. It was also used to describe general information for users by converting non-quantitative data into a quantity that can be measured through a questionnaire designed specifically to serve the purposes and directions of the study. This questionnaire was in line with the hypotheses of the study, and the inferential approach as it helps analyzing and interpreting the digital data of a sample and circulating those results to the study population. Data analysis and extraction were carried out using the Statistical Package for Social Sciences (SPSS).

\subsection{Population and sample study}

The study population consisted of employees working in the internal audit and IT departments of all the 13 commercial banks listed in the Amman Financial Market -the most prominent banking developments in Jordan during 2018, 2019- with 849 employees that were identified by the sampling technique by communicating with all human resources in the banks under consideration. The table introduced by Krejcie and Morgan (1970) was used to determine the sample size at an error level equivalent to (5\%), and a confidence level (95\%). The sample size was 265 . The two researchers adopted the (descriptiveanalytical) approach to identify the effect of the independent variables on the dependent variable. The data was provided through a controlled electronic psychometric questionnaire from a group of experts in the field of artificial intelligence and cybercrime. 
After questionnaire distribution, 240 responses were obtained. 10 unsuitable responses were excluded. Thus, the responses are (230) with an excellent response rate (86.7\%) (Blaikie \& Priest, 2019).

The questionnaire consisted of two parts: The first part is about demographic information including gender, field of work, age, educational level and experience of the sample members. While the second part carried (20) questions distributed over the four dimensions of the independent variable and (10) questions for the dependent variable. To measure "artificial intelligence and cybercrime," the five-point Likert scale (strongly agree, agree, neutral, disagree, strongly disagree) was used, which is digitally marked by $(1,2,3,4,5)$.

The characteristics of the study sample were represented as follows.

The percentage of male respondents was (75.7\%) of the study sample, while the female respondents constituted (24.3\%) of the sample. The percentage of auditors from the sample was $(47.8 \%)$, while the percentage of IT was $(52.1 \%)$. The age group (25 years to less than 39) represented the majority by (69.6\%), followed by the age group (39 years to less than 59 years) with a percentage of (58\%), while the age group (less than 25) recorded the lowest percentage by $(5.2 \%)$. We note from the table that BA holders formed the highest percentage of the study sample, as their percentage was (78.7\%), followed by the MA holders with $(15.2 \%)$ of the sample individuals. The researchers believe that the reason for the increase in the percentage of bachelor's goes back to the job positions at banks which does not require qualifications higher than BA. Most of the participants work in the auditing and information technology sector. The diploma or less category came in third place with a rate of (4.3\%), while the $(\mathrm{PhD})$ category ranked last in the study sample with a rate of $(1.7 \%)$. The responses of those with periods of experience (from 10 to less than 15 years) represented the highest rate (33\%), followed by the responses of those with periods of experience (from 5 to less than 10 years) by (27\%), then responses of those with periods of experience (greater than 15 years). Years) by $(23.9 \%)$, and we also note that the last category ( 5 years and less) came in the lowest rank with a rate of $(16.1 \%)$.

\subsection{Data collection sources}

The study data were collected from the questionnaire as a primary source, and from books, articles and websites as secondary sources.

\subsection{Statistical analysis of data}

The researcher used the following statistical methods in analyzing data and testing hypotheses according to the SPSS program:

1. Reliability: The Cronbach alpha test was conducted to measure the quality of the paragraphs of the questionnaire, their internal consistency, and their stability in measuring the dimensions. The Cronbach alpha values for all the study variables ranged between $(70.1 \%-89.5 \%)$ and this indicates that there is an internal consistency between the paragraphs of the questionnaire according to (Sekaran \& bougie, 2016, 184)

2. Pearson Test: One of the conditions for moving towards a linear regression analysis is to ensure that there is no almost perfect linear correlation between two or more variables. For this, Pearson examination was performed and it was noticed that the correlation coefficients did not exceed (0.80). Therefore, there is no correlation problem of multiple high linearity. (Guajarati, 2004, 359)

3. VIF Test: To ensure that the sample is free from the multiple correlation problem, the Variance Inflation Factor (VIF) was calculated. The values of the VIF were all greater than the number (1) and less than the number (10) and ranged between (1.258$1.796)$ as well. The Tolerance value was limited between $(0.1-1)$ and ranged between $(0.557-0.795)$. This indicates that there is no problem of multiple linear correlation between all the variables of the independent study (Guajarati, 2004, 359).

\section{Hypothesis testing}

The study hypotheses were tested using three methods Multiple Regression, Simple Regression and Independent sample T-Test:

\subsection{Multiple Regression}

As shown in Table 1, the statistical value (F) reached 45.33 with a significance level of (0000), which is less than (0.05). Consequently, it rejects the null hypothesis and accepts the alternative, indicating that there is an impact of the AI dimensions on cybercrime in Jordanian commercial banks. B values show that Expert Systems, Artificial Neural Network, and Genetic Algorithm (0.242, 0.206, 0.273), respectively, are significant. A statistic at a significance level ( $\alpha \leq 0.05)$, while no effect of the Fuzzy logic dimension was found. Depending on the value of R2, the explanatory ability of the artificial intelligence to explain the variance in competitive advantage reached (45\%) though it remained constant for the other factors. This confirms the importance of banks' expansion in the use of modern technology and applications of artificial intelligence to reduce Cyber fraud. 
Table 1

Multiple Regression Results

\begin{tabular}{|c|c|c|c|c|c|}
\hline Variables & B & SE & Beta & $\mathbf{t}$ & Sig. \\
\hline Expert Systems & 0.242 & 0.045 & 0.315 & 5.417 & 0.000 \\
\hline Artificial Neural Network & 0.206 & 0.057 & 0.209 & 3.599 & 0.000 \\
\hline Genetic Algorithm & 0.273 & 0.051 & 0.311 & 5.318 & 0.000 \\
\hline Fuzzy logic & 0.049 & 0.044 & 0.062 & 1.112 & 0.267 \\
\hline
\end{tabular}

$\mathrm{R}$ Square $=0.668$ Adjusted R Square $=0.436 \mathrm{~F}$ Statistic $=45.33(0.000)$

\subsection{Simple regression}

The researchers conducted a simple regression analysis to examine the effect of each dimension of the independent variable represented by artificial intelligence on the dependent change represented in cybercrime. The results were as follows:

First hypothesis test: It was found that the value of the determination coefficient (R2) has explained a percentage (0.290) of the variance in the dependent variable, meaning that what is valued (29\%) of the changes in cyber fraud resulting from Expert Systems. Therefore, we reject the hypothesis which states that there is no statistically significant effect at the level of statistical significance $(\alpha \leq 0.05)$ Expert Systems on cyber fraud in Jordanian commercial banks and we accept the alternative hypothesis. This is in agreement with the results of the study Šubelj et al. (2011) and Ebrahiem (2018) and Al-Beshtawi and AL-Baqmi (2018). The second hypothesis test: It was found that the value of the determination coefficient (R2) is (0.189) of the variance in the dependent variable. This pinpoints that what is valued (18.9\%) of the changes in cyber fraud resulted from the Artificial Neural Network. Consequently, we reject the hypothesis which states that there is no statistically significant effect at the level of statistical significance $(\alpha \leq 0.05)$ Artificial Neural Network on cyber fraud in Jordanian commercial banks and we accept the alternative hypothesis. This is in agreement with the study (Ford et al., 2014).

Third hypothesis test: It was found that the value of the determination coefficient $\left(\mathrm{R}^{2}\right)$ has explained $(0.298)$ of the variance in the dependent variable, meaning that its value (29.8\%) of the changes in cyber fraud resulted from Genetic Algorithm. Therefore, we reject the hypothesis that there is no statistically significant effect at the level of statistical significance $(\alpha \leq 0.05)$ Genetic Algorithm on cyber fraud in Jordanian commercial banks and we accept the alternative hypothesis. This is in agreement with Paasch (2008) and Minastireanu and Mesnita (2019).

Fourth hypothesis test: It was found that the value of the determination coefficient $\left(\mathrm{R}^{2}\right)$ has explained $(0.067)$ of the variance in the dependent variable, that is, what is valued (6.7\%) of the changes in cyber fraud resulting from Fuzzy logic. Thus, we reject the hypothesis that there is no statistically significant effect at the level of statistical significance $(\alpha \leq 0.05)$ Fuzzy logic on cyber fraud in Jordanian commercial banks and we accept the alternative hypothesis. This is consistent with a study (Askari \& Hussain, 2020) on fraud detection.

Table 2

Simple Regression Results

\begin{tabular}{cccccc}
\hline Hypothesis & $\mathbf{R}$ & $\mathbf{R}^{\mathbf{2}}$ & $\mathbf{t}$ & Sig. & Decision \\
\hline H1 & 0.539 & 0.290 & 9.652 & 0.000 & Reject Null \\
H2 & 0.435 & 0.189 & 7.299 & 0.000 & Reject Null \\
H3 & 0.546 & 0.298 & 9.846 & 0.000 & Reject Null \\
H4 & 0.258 & 0.067 & 4.039 & 0.000 & Reject Null \\
\hline
\end{tabular}

\subsection{Independent sample T-Test}

Table 3

Test of Variance Analysis between Internal Auditors and IT department employees towards the Study Hypotheses

\begin{tabular}{cccccccc}
\hline Hypothesis & Type & Mean & $\begin{array}{c}\text { Standard } \\
\text { Deviation }\end{array}$ & df & t Value & Sig. level & Result \\
\hline H1 & IT & 4.0683 & 0.44419 & 228 & 0.944 & 0.346 & 0.346 \\
& Auditor & 4.0164 & 0.38517 & & & 0.101 & 0.101 \\
H2 & IT & 3.8967 & 0.52307 & 220.53 & 1.646 & 0.010 & 0.010 \\
H3 & Auditor & 3.7964 & 0.39722 & 228 & 2.614 & 0.152 & 0.152 \\
H4 & IT & 3.9367 & 0.41807 & 228 & 1.437 & 0.018 \\
Auditor & IT & 3.7964 & 0.39351 & 2.7483 & 0.55519 & 2.384 & 0.018 \\
\hline
\end{tabular}


According to Table 3 above, we note that the $(\mathrm{t})$ values were not statistically significant at a level less than 0.05 in Expert Systems, Artificial Neural Network and Fuzzy logic, which indicates that there are no statistically significant differences for these dimensions attributable to the job variable. While the $(\mathrm{t})$ values were statistically significant at a level less than 0.05 in both Genetic Algorithm and Cyber fraud, indicating the existence of statistically significant differences for these dimensions attributed to the job variable in favor of the IT department employees (Goldmann \& Kaufman, 2009).

\section{Conclusion and Recommendation}

The analysis of the arithmetic mean and standard deviations of the questionnaire questions indicated that banks' expert systems are based on advanced information systems that develop solutions to various problems. However, they seem to be used at a lower rate, as a consultant to improve the decision-making process in the banking sector. The study confirmed that artificial neural networks are characterized by the ability to derive information from complex data, but they act as information systems that simulate human nerves and the self-learning method of brain processing to a moderate degree.

The study highlighted that genetic algorithms work according to an algorithm in which solutions and possible alternatives to the decision compete to reach the best solution. It also enables the bank to access options and alternatives in relation to non-digital issues. The banks under study agreed on the role of ambiguous logic in processing the disguised data, but it helps to make the right decisions in an environment characterized by the complexity of information with a moderate degree. This paper confirmed that there is written code of conduct that clarifies the work ethics in the bank. Similarly, the bank also provides adequate training that reduces the chance of the customer being exposed to fraud, but to a lesser extent. By reviewing the results of the statistical analysis and the results of testing the study's hypotheses, it can be understood that there is an important effect of artificial intelligence in Limiting cybercrime in Jordanian commercial banks, as it was found through the results of hypothesis testing that the four components of artificial intelligence (represented in expert systems, networks). The findings indicated that the dimension of expert systems was in the first rank in terms of their existence, followed by the dimension of genetic algorithms, and in the third rank was the dimension of fuzzy logic. The fourth rank was taken by the dimension of neural networks and all these aspects were highly rated. The results also demonstrated a high level of appreciation for cybercrime. The below are the results in details:

All artificial intelligence in its combined dimensions were explained except for the Fuzzy logic dimension by testing a simple regression (44.5\%) of the impact on cybercrime in Jordanian commercial banks, and this is in agreement with Kumar et al. (2019), Haenlein and Kaplan (2019) and Huang and Rust (2018),

The dimensions of artificial intelligence (represented in expert systems, neural networks, genetic algorithms, and fuzzy logic), by simple regression testing, explained the impact of cybercrime in Jordanian commercial banks as (29\%) (19\%) (29.8\%) $(6.7 \%)$. This is consistent with the findings of Ajam (2018). This confirms its effective role in dealing with complex problems, finding appropriate solutions in record time, rational thinking, speed in decision-making, fraud detection and limiting fraud. It was also found that there are statistically significant differences for both Genetic Algorithm and Cyber fraud due to the job variable in favor of IT department employees.

The study recommends the necessity to activate the use of artificial intelligence dimensions in financial institutions because of their effect on Limiting fraud, high accuracy and the ability to verify the reliability of financial reports. Focusing on developing neural networks to mimic human nerves and human learning methods. It also recommended working on strengthening the application of the fuzzy logic dimension and focusing on developing neural networks to simulate human nerves and human learning methods.

\section{References}

Abderrahmane, L. (2017). The New Roles For The Internal Auditor in Order to Reduce Cheating in Business Organizations in the Light of New Requirements for the Internal Audit Profession. Arab Journal of Administration, $37(1), 5$.

Ajam, M. D. I. M. H. (2018). Artificial Intelligence and its Implications for High Performance Organizations-Exploratory Study in the Ministry of Science and Technology. Journal of Administration and Economics, 115.

Al-Bishtawi, S. H., Al-Buqami, M.A. (2015). The effect of applying expert systems in commercial banks on electronic audit procedures from the viewpoint of external certified accountants, a comparative study in the Hashemite Kingdom of Jordan and the Kingdom of Saudi Arabia. Jordan Journal of Business Administration, 11(1).

Askari, S. M. S., \& Hussain, M. A. (2020). IFDTC4. 5: Intuitionistic fuzzy logic based decision tree for E-transactional fraud detection. Journal of Information Security and Applications, 52, 102469.

Balayan, V. (2020). Human-Interpretable Explanations for Black-Box Machine Learning Models: An Application to Fraud Detection (Doctoral dissertation, Universidade Nova de Lisboa). 
Belabed, F., \& Shawi, H. (2019). The role of expert systems in evaluating the performance of economic institutions. A collective book titled: Applications of artificial intelligence as a modern trend to enhance the competitiveness of business organizations, P85-100.

Buzerb, Kheireldeen, \& Sahnon, Hiba. (2019). Artificial Intelligence and its Applications in the Banking Sector: Reading in the Indian Experience, HDFC Bank Case Study. A collective book titled: Applications of artificial intelligence as a modern trend to enhance the competitiveness of business organizations, P149-168.

Cazenave, T. (2011). Intelligence artificielle: une approche ludique. Ellipses.

Crevier, D. (1993). AI: the tumultuous history of the search for artificial intelligence. Basic Books, Inc..

Ebrahiem, A. (2018). The Role Of Using The Expert Systems In Improving The Quality Of The Managerial Decision A Field Study On The Banks Operating In The Syrian Coast. Tartous University Journal for Research and Scientific Studies Economic and Legal Sciences Series, 2(4) 2028.

Ford, V., Siraj, A., \& Eberle, W. (2014, December). Smart grid energy fraud detection using artificial neural networks. In 2014 IEEE Symposium on Computational Intelligence Applications in Smart Grid (CIASG) (pp. 1-6). IEEE.

Gamoura, S., Bey, M., \& Kroush, H. (2018, February). Artificial Intelligence: Between the Reality and Hope Practical and Technical Studies in Management. International Forum "Artificial Intelligence: A New Challenge to Law", Algeria.

Goldmann, P., \& Kaufman, H. (2009). Anti-fraud risk and control workbook. John Wiley \& Sons.

Haenlein, M., \& Kaplan, A. (2019). A brief history of artificial intelligence: On the past, present, and future of artificial intelligence. California Management Review, 61(4), 5-14.

Huang, M. H., \& Rust, R. T. (2018). Artificial intelligence in service. Journal of Service Research, 21(2), 155-172.

IDC. (2020). Worldwide Artificial Intelligence Spending Guide. Framingham. Retrieved from https://www.idc.com/getdoc.jsp?containerId=IDC_P33198

Ismail, M. M., \& Ghanawi, H. A. (2019). Building the optimal portfolio of stocks using the multi-purpose genetic algorithm comparative analytical research on the Iraq Stock Exchange. Journal of Economics and Administrative Sciences, 25(113), 45-78.

Deesing, J. (2019). What is Artificial Intelligence?. www.lifewire.com, retrieved 7-10-2019.

Joyce, J. L., \& Harris, L.A. (2018). Artificial Intelligence (AI) and education. In Focus, Congressional Research service, August. Retrived from www.crs.gov

Jubouri, N., \& Salman, F. (2017). Expert systems and their impact on accounting information systems, Journal of the University Heritage College, 21, 279-300.

Geyskens, I., Keller, K. O., Dekimpe, M. G., \& de Jong, K. (2018). How to brand your private labels. Business horizons, 61(3), 487-496.

Kumar, V., Rajan, B., Venkatesan, R., \& Lecinski, J. (2019). Understanding the role of artificial intelligence in personalized engagement marketing. California Management Review, 61(4), 135-155.

Krejcie, R. V., \& Morgan, D. W. (1970). Determining sample size for research activities. Educational and Psychological Measurement, 30(3), 607-610.

Lee, H., Choi, D., Yim, H., Choi, E., Go, W., Lee, T., ... \& Lee, K. H. (2018). Feature selection practice for unsupervised learning of credit card fraud detection. Journal of Theoretical and Applied Information Technology, 96(2), $408-417$.

Madkour, M. (2020). The future of humanity in the light of Strong Artificial Intelligence projects: Journal of Studies in the Humanities and Social Sciences, 3(1), 138-166.

McKinsey. April 23, 2020

Mendel, J. (2010). A short Fuzzy Logic Tutorial. April 2010

Minastireanu, E. A., \& Mesnita, G. (2019). An Analysis of the Most Used Machine Learning Algorithms for Online Fraud Detection. Informatica Economica, 23(1).

Misra, A. K., \& Sebastian, V. J. (2013). Portfolio optimization of commercial banks-an application of genetic algorithm. European Journal of Business and Management, 5(6), 120-129.

Morgan, R. (2018). What is Cyber Fraud? | DeltaNet. DeltaNet International. https://www.delta-net.com/compliance/fraudawareness/faqs/what-is-cyber-fraud

MS, D. (2019). Application of Robotics in Accounting and Auditing of Business and Financial Information.

O'brien, J. A., \& Marakas, G. M. (2005). Introduction to information systems (Vol. 13). New York City, USA: McGrawHill/Irwin.

O'brien, J. A., \& Marakas, G. M. (2006). Management information systems (Vol. 6). McGraw-Hill Irwin.

Omoteso, K. (2012). The application of artificial intelligence in auditing: Looking back to the future. Expert Systems with Applications, 39(9), 8490-8495.

Osman, H., \& Jamil, A. (2012, April). The possibility of using artificial intelligence techniques to control the quality of internal audit. In The eleventh annual scientific conference, Al-Zaytoonah University, Amman, Jordan (pp. 23-26).

Öztürk, M. S., \& Usul, H. (2020). Detection of Accounting Frauds Using the Rule-Based Expert Systems within the Scope of Forensic Accounting. In Contemporary Issues in Audit Management and Forensic Accounting. Emerald Publishing Limited.

Paasch, C. A. (2008). Credit card fraud detection using artificial neural networks tuned by genetic algorithms. Hong Kong University of Science and Technology (Hong Kong). 
Passino, K. M., Yurkovich, S., \& Reinfrank, M. (1998). Fuzzy control (Vol. 42, pp. 15-21). Reading, MA: Addison-Wesley.

Ramya, B., \& Umarani, V. (2017). Childhood Bone Marrow And Artificial Neural Network: IOSR Journal of Computer Engineering (IOSR-JCE), 5(1), 58-60

Russell, S., \& Norvig, P. (2002). Artificial intelligence: a modern approach.

Sayamtini (12-7-2019) .Top 12 Artificial Intelligence Tools \& Frameworks you need to know.www.edureka.co, Retrieved 710-2019. Edited.

Shnawa, Wesam \& AlBakri, Reyad. (2018). The role of artificial intelligence in achieving Customer satisfaction and its reflection on cost accounting An applied research in the Iraqi electronic industries company. Journal of Accounting and Financial Studies, 13(45).

Šubelj, L., Furlan, Š., \& Bajec, M. (2011). An expert system for detecting automobile insurance fraud using social network analysis. Expert Systems with Applications, 38(1), 1039-1052.

Varmedja, D., Karanovic, M., Sladojevic, S., Arsenovic, M., \& Anderla, A. (2019, March). Credit card fraud detection-machine learning methods. In 2019 18th International Symposium INFOTEH-JAHORINA (INFOTEH) (pp. 1-5). IEEE.

https://www.aitrends.com/financial-services/ai-in-fintech-helping-detect-fraud-assess-risk/\#

\section{Appendix}

Paragraphs Related to the Hypotheses of the study

\begin{tabular}{|c|c|c|c|c|c|}
\hline Dim. & Items of Customer Focus & Mean & $\begin{array}{c}\text { Std. } \\
\text { deviation }\end{array}$ & Rank & Level \\
\hline ES & Expert systems are based on advanced information systems that develop solutions to various problems. & 4.2130 & 0.5143 & 1 & High \\
\hline ES & It is through expert systems that human experience in problem-solving is modeled. & 4.1174 & 0.5829 & 2 & High \\
\hline ES & Expert systems are used as a consultant to improve decision-making in the banking sector. & 3.9520 & 0.6819 & 5 & High \\
\hline ES & Expert systems assist in gaining knowledge in several areas to support the capabilities of senior management & 3.9826 & 0.6606 & 3 & High \\
\hline ES & Expert systems aid managers in the thinking process and not just providing them with information. & 3.9524 & 0.7373 & 4 & High \\
\hline ANN & $\begin{array}{l}\text { Artificial neural networks act as information systems that imitate the human nerves and the way the brain is } \\
\text { processed. }\end{array}$ & 3.6130 & 0.7608 & 5 & Medium \\
\hline ANN & Artificial neural networks have the ability to derive information from complex data. & 4.0696 & 0.4984 & 1 & High \\
\hline ANN & $\begin{array}{l}\text { Artificial neural network systems help banks obtain large amounts of information to create specific characteristics } \\
\text { and situations. }\end{array}$ & 3.9870 & 0.5244 & 2 & High \\
\hline ANN & Artificial neural network systems have the advantage of learning, as in human cases. & 3.6565 & 0.8144 & 4 & Medium \\
\hline ANN & Artificial neural networks provide banks with multiple options due to their high ability to analyze information. & 3.9174 & 0.6976 & 3 & High \\
\hline GA & $\begin{array}{l}\text { Genetic algorithms work according to an algorithm in which solutions and possible alternatives to the decision } \\
\text { compete to arrive at the best solution. }\end{array}$ & 4.0217 & 0.5241 & 1 & High \\
\hline GA & Genetic algorithms help banks find solutions quickly in the changing environment. & 3.9261 & 0.6398 & 3 & High \\
\hline GA & Genetic algorithms enable the bank to access options and alternatives for non-digital issues & 3.6957 & 0.6498 & 5 & High \\
\hline GA & $\begin{array}{l}\text { Genetic algorithms develop themselves and adapt quickly to the environment to keep pace with regulatory } \\
\text { developments }\end{array}$ & 3.7000 & 0.7658 & 4 & High \\
\hline GA & Genetic algorithms are an excellent tool to help a bank reach results quickly when there is a lot of input. & 4.0043 & 0.5873 & 2 & High \\
\hline FL & Fuzzy logic systems are sophisticated information systems based on non-constructive or imperfect values & 3.6391 & 0.7149 & 4 & Medium \\
\hline FL & $\begin{array}{l}\text { Fuzzy logic processes intermediate data that cannot be processed by traditional computer programs that operate } \\
\text { with structural values }(0.1) \text {. }\end{array}$ & 3.8130 & 0.6960 & 1 & High \\
\hline FL & Fuzzy logic systems help make the right decisions in an information-complex environment & 3.6000 & 0.7394 & 5 & Medium \\
\hline FL & $\begin{array}{l}\text { Commonly used fuzzy logic systems in the bank are used in combination with other AI applications such as expert } \\
\text { systems. }\end{array}$ & 3.6652 & 0.8338 & 3 & Medium \\
\hline FL & $\begin{array}{l}\text { Fuzzy logic systems are used in several areas of the bank, such as forecasting in risk management, liquidity } \\
\text { management }\end{array}$ & 3.7826 & 0.7273 & 2 & High \\
\hline $\mathrm{CF}$ & There is a written code of conduct outlining the business ethics of the bank. & 4.4957 & 0.5509 & 1 & High \\
\hline $\mathrm{CF}$ & The bank's management is working on implementing continuous exercises to raise awareness about cybercrime. & 4.3652 & 0.7457 & 4 & High \\
\hline $\mathrm{CF}$ & The bank's employment policies include checking the credit background of new employees. & 4.1435 & 0.7542 & 9 & High \\
\hline $\mathrm{CF}$ & The bank's management follows a zero-tolerance approach to cybercrime issues. & 4.3870 & 0.7375 & 3 & High \\
\hline $\mathrm{CF}$ & The bank uses external auditors to ensure the progress of electronic operations. & 4.1739 & 0.8743 & 8 & High \\
\hline $\mathrm{CF}$ & The bank works to reduce a customer's exposure to fraud by providing adequate training. & 4.1261 & 0.7800 & 10 & High \\
\hline $\mathrm{CF}$ & There are measures that contribute to Limiting entry related fraud such as wrong entry of payments and receipts & 4.2174 & 07213 & 7 & High \\
\hline $\mathrm{CF}$ & $\begin{array}{l}\text { The banking supervision system helps to reduce operator fraud and reduce operator exploitation by internal and } \\
\text { external parties }\end{array}$ & 4.3000 & 0.6749 & 5 & High \\
\hline $\mathrm{CF}$ & The banking system works to reduce instruction and software fraud and penetration of the banking system & 4.2652 & 0.6298 & 6 & High \\
\hline $\mathrm{CF}$ & $\begin{array}{l}\text { There is a protection shield from breaching customer data, accounts, and balances and making any movements on } \\
\text { them }\end{array}$ & 4.4087 & 0.6726 & 2 & High \\
\hline
\end{tabular}

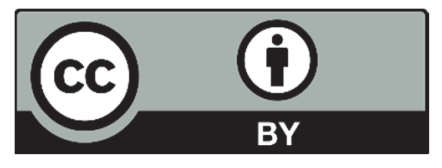

(C) 2021 by the authors; licensee Growing Science, Canada. This is an open access article distributed under the terms and conditions of the Creative Commons Attribution (CC-BY) license (http://creativecommons.org/licenses/by/4.0/). 